\title{
EFFECT OF CONFINEMENT ON THE INTERACTION DIAGRAMS FOR RC SECTIONS WITH CFRP GRIDS
} AND WRAPS

\author{
P. CHRISTOU, A. MICHAEL, C. ANASTASIOU \& D. NICOLAIDES \\ Department of Civil Engineering, Frederick University, Cyprus.
}

\begin{abstract}
Application of CFRP composite materials is a popular method of strengthening reinforced concrete members. Wrapping columns with these materials is used in seismic retrofits because of the increase in the strength and ductility of concrete, and therefore, of the column itself. This is particularly beneficial for compression-controlled columns that fail by concrete crushing due to the fact that ductility and strength of the member is significantly improved. For the design of columns, interaction diagrams are used which define the maximum capacity of compression members that are subjected to axial force and bending moments. This work includes the development of interaction diagrams for circular compression members confined with CFRP composites. The concrete confinement can be light (low confinement pressure) or heavy (high confinement pressure). In this paper, three levels of confinement are evaluated: (a) zero confinement, (b) light confinement with the use of a CFRP composite grid, and (c) heavy confinement with the use of CFRP composite wraps with two different thicknesses of the wrap. A comparison of the unconfined section to the light and heavily confined sections shows a considerable difference primarily in the compression-controlled region where the axial compression and bending moment are significantly enhanced. The balance point for both light and heavy confinement has moved higher up on the interaction diagram, which changes the range of the compression and tension zones. This is evident for both light and heavy confinement. Also, the failure mode of compression-controlled columns is more ductile because of the change in the behavior of concrete due to confinement.

Keywords: CFRP, Confinement, Interaction Diagram, RC Section Strength.
\end{abstract}

\section{INTRODUCTION}

Confinement of concrete is an important factor that can change the failure mode of columns due to the increase in ductility of confined concrete. When columns with no confinement fail in a compression-controlled mode (failure by concrete crushing), they exhibit non-ductile behavior, while columns with confinement exhibit ductile behavior even when failing by concrete crushing.

The analysis of concrete columns using an analytical solution is not an easy task. As a result, the analysis of columns is based primarily on the development and use of interaction diagrams and the plot of the load condition in order to define failure of the section. Normally, the confinement for compression members made from reinforced concrete is provided either by ties or spirals. However, other methods and materials are used in the later years, which can provide increased confinement, and thus satisfy the requirement for increased ductility. The column wrapping with carbon-fiber-reinforced polymers (CFRP) composites is a popular alternative for improving the ductility and strength of the concrete material, and thus the seismic resistance of columns. The increased strength of concrete due to the confinement provided by the CFRP composite material is usually ignored or not taken into account on the development of interaction diagrams for new members. This work attempts to investigate and present the effect of confinement on the interaction diagrams of sections confined by CFRP composite materials. 
Fiber fabrics and prefabricated fiber-reinforced polymer (FRP) composite jackets or tubes cover the entire area of the concrete element, and therefore cannot be embedded in concrete but rather applied on the outside surface of the member. Another technique is the use of a CFRP composite grid by Michael et al. [1]. The carbon grid has approximately $69 \%$ open surface area allowing the grid to be embedded in the concrete. Light grids are easily formed into a round shape and can provide more effective confinement than wraps that are forced to follow the column cross-section, which might be square or rectangular.

The work presented herein refers to a numerical procedure for the development of interaction diagrams of concrete sections that are confined with CFRP and provide a comparison with similar sections without confinement. Three levels of confinement are used and compared to the unconfined section. The zero confinement level is the section without any confinement reinforcement, which is used as the control section for comparison purposes. The second level is light confinement to concrete using a light CFRP composite grid, a technique used by Michael et al. [1]. The third level is heavy confinement to concrete using CFRP wraps. Two different thicknesses of the CFRP composite wrap are evaluated.

\subsection{Approximate analyses for columns}

A search in the literature reveals a number of numerical approximations for the development of such diagrams. In the three-dimensional case, these methods rely on using single-axis bending response in the two principal directions for the approximation of the biaxial bending. Some of these methods are:

- The Bresler load contour method [2]

- The Bresler reciprocal load method [2]

- The PCA load contour method [2]

- The Weber design charts [3]

\subsection{Confined concrete}

Confinement can improve both the compressive strength and ductility of concrete. Steel has typically been used to confine the concrete in reinforced concrete columns. Steel can be internal reinforcement, usually used as a spiral or ties, or it can be external such a steel jacket that is bonded to the outside face of the column. When FRP materials became widely available in the civil sector, they started replacing steel as external confinement reinforcement. One of the primary applications of FRP materials is retrofit of concrete elements, primarily columns, to improve their ductility. This is done mainly in seismic regions where concrete structures experience large deformations. Column wrapping improves the strength and ductility of the concrete and improves its performance under earthquake loads. Xiao and $\mathrm{Wu}[4,5]$ wrapped concrete cylinders using various materials and methods. Some were wrapped with carbon fiber fabrics, while others were wrapped with glass fiber fabrics. They also wrapped cylinders using a machine that tightly wound carbon fibers around the cylinders. The results showed a significant improvement both in strength and ductility. Lam and Teng [6], Li, Lin, and Sung [7], and Harries and Kharel [8] wrapped cylinders with carbon fabrics and observed similar results as Xiao and Wu. Li and Hadi [9] and Campione and Miraglia [10] tested round concrete columns wrapped with either glass or carbon fiber fabric sheets in a polymer matrix. In doing so they improved the ductility of the columns. Campione and Miraglia [10] also wrapped, in the same 
manner, square columns and square columns with round corners with the same results. It was found that the round shape is the most effective shape for confinement, while the square with sharp corners is the least effective of the three. Teng, Sotelino, and Chen [11] wrapped bridge columns in the field using FRP wraps. Laboratory specimens were also tested with the columns exhibiting a ductile behavior. Shahawy, Mirmiran, and Beitelman [12] tested standard concrete cylinders wrapped with carbon fiber fabrics in an epoxy matrix. The results varied depending on the number of carbon layers applied. For an unconfined concrete strength of 41.4 MPa the confined strength of cylinders was increased to $70 \mathrm{MPa}$ for the one-layer wrap and $110 \mathrm{MPa}$ for the four-layer wrap. The ultimate strain for the one-layer wrap was $0.007 \mathrm{~mm} / \mathrm{mm}$ and that for the four-layer wrap was $0.016 \mathrm{~mm} / \mathrm{mm}$. Prefabricated FRP tubes can be filled with concrete and serve at the same time as formwork, flexural reinforcement, and confinement reinforcement. Davol, Burgueno, and Sible [13] tested prefabricated round shells filled with concrete in flexure with satisfactory results. The concrete-filled FRP shells exhibited a ductile behavior. Michael, Hamilton, and Ansley [1] used a light CFRP composite grid to confine concrete. Through a series of cylinder tests they found that the grid provides light confinement to concrete. The crushing strain of confined concrete was twice as high compared to the unconfined concrete tested. Michael, Hamilton, and Ansley [1] used the CFRP composite grid in a series of flexural members and noted improvements in member ductility of more than $30 \%$ with minimal confinement reinforcement.

\section{INTERACTION DIAGRAMS}

The interaction diagram (Fig. 1) is a graphical representation of the ultimate capacity of a column subjected to axial load (Pn) and uniaxial bending (Mn). The interaction diagram depends on the concrete cross-sectional area, the material properties (stress and strain) and

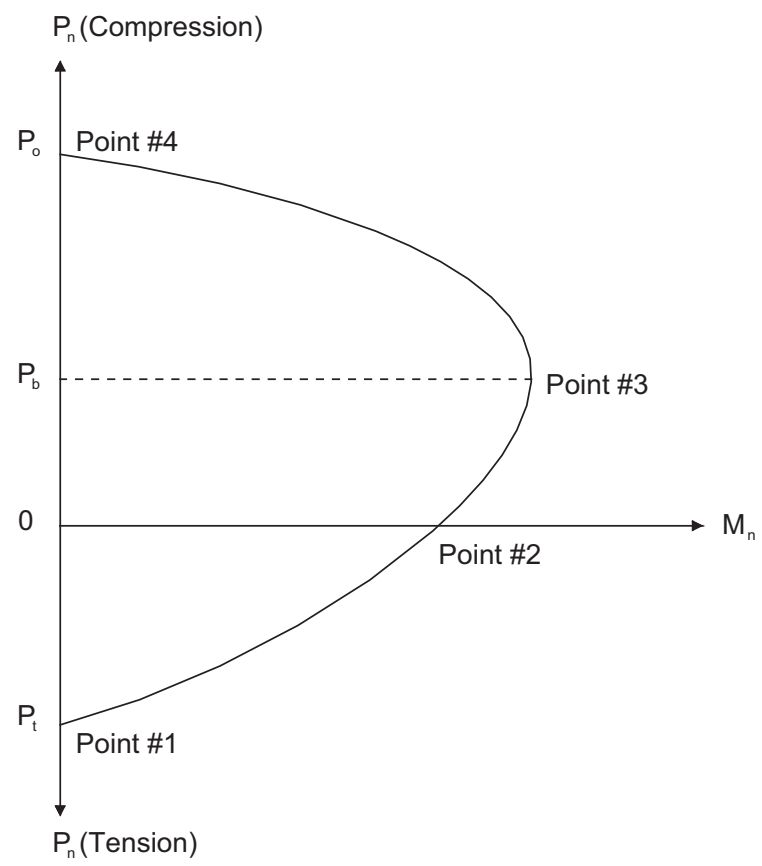

Figure 1: Representation of the interaction diagram. 
also the amount and distribution of reinforcement. Therefore, each concrete section with a specific reinforcement distribution is characterized by a unique interaction diagram representing failure as crushing of concrete at the maximum compressive strain. After the determination of design loads (P, M), three possible load conditions plotted as points can be defined once the interaction diagram for a section is obtained:

- The load condition coincides with the interaction diagram curve: represents the limit state.

- The load condition falls inside the interaction diagram curve: causes no failure in the section.

- The load condition falls outside the interaction diagram curve: causes failure in the section.

The interaction diagrams can also be extended to three-dimensional surfaces to account for biaxial bending. The principle regarding the load conditions remains the same.

\section{REQUIREMENTS FOR THE DEVELOPMENT OF INTERACTION DIAGRAMS}

The following conditions, assumptions and limitations, definition of the stress versus strain relations of the material as well as definition of the plastic centroid of the section are required for the development of interaction diagrams.

\subsection{Conditions}

Following conditions must be satisfied in the development of interaction diagram.

- Force equilibrium

- Strain compatibility

- Stress vs strain relationships

\subsection{Assumptions and limitations}

The following assumptions and limitations are applied.

- Plane sections remain plane

- The strain in the reinforcement is the same as that of the adjacent concrete interface

- The contribution of the tension zone to the bearing capacity of the section is neglected

- Failure occurs in the concrete at maximum compressive strain

\subsection{Stress vs strain properties}

In this section, the stress-strain relationships for the materials are presented. The sections that are examined refer to reinforced column sections without any confinement and then compared to similar sections that are confined with CFRP.

\subsubsection{Concrete}

The stress-strain relationship in the concrete that is used in this work is represented by the parabola defined by Hognestad, as this is defined in the literature [14]. The tensile part of the graph is neglected. In order to define the curve it is required to have the concrete strength $\left(\mathrm{f}_{\mathrm{c}}^{\prime}\right)$, the strain at peak stress, $\varepsilon_{o}$, and the concrete modulus of elasticity $\left(\mathrm{E}_{\mathrm{c}}\right)$. 


\subsubsection{Steel}

The stress-strain relationship is assumed to be elastic-plastic, and it is the same in tension and compression [14]. In order to define this curve, it is required to define the steel yield stress $\left(f_{y}\right)$ and the modulus of elasticity of steel $\left(E_{s}\right)$.

\subsubsection{CFRP composite grid}

Column wrapping with CFRP composites is a popular alternative for improving the seismic resistance of columns. Fiber fabrics and prefabricated FRP composite jackets or tubes cover the entire area of the concrete element, and therefore cannot be embedded in concrete. The carbon grid has approximately $69 \%$ open surface area allowing the grid to be embedded in the concrete. Light grids are easily formed into a tubular shape and can provide more effective confinement than wraps that are forced to follow the column cross-section, which might be square or rectangular. This is a new technique that requires investigation of the level of confinement provided by the grids. While there are a number of analytical models available, it is important to conduct testing on concrete samples confined with the light grids to confirm a model that will accurately predict concrete behavior for this specific case. Carbon grid properties are essential to any model to determine concrete behavior, which needs to be determined through testing.

The CFRP composite grid tested in this program was fabricated from carbon fibers embedded in an epoxy matrix. It was supplied in the form of rolls that are $1.041 \mathrm{~m}$ wide and 274.32 $\mathrm{m}$ long. The strand spacing in the longitudinal direction was $45.7 \mathrm{~mm}$ and in the transverse direction $40.6 \mathrm{~mm}$. The CFRP grid had an openness of $69 \%$, which means that only $31 \%$ of the surface area was covered by the carbon fibers.

Tensile properties of the grid were determined by testing two strands of rectangular cross section from each direction using the specimen configuration shown in Fig. 2(a). Each end of

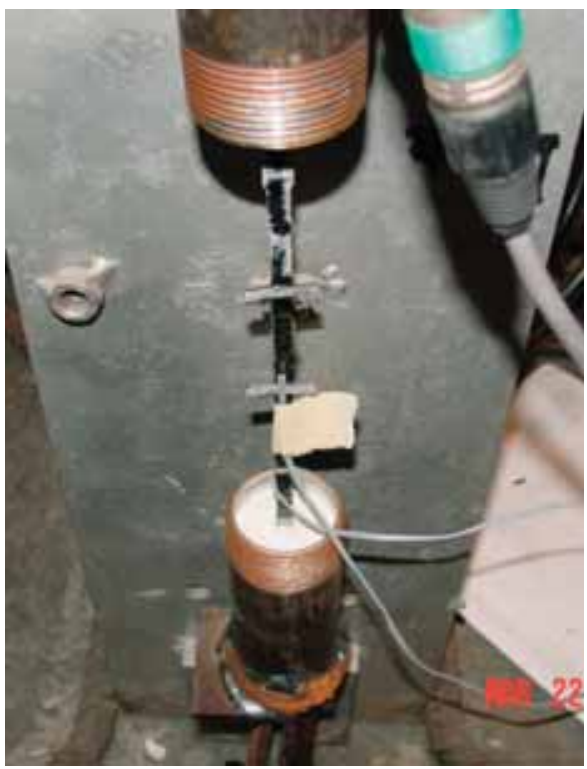

(a)

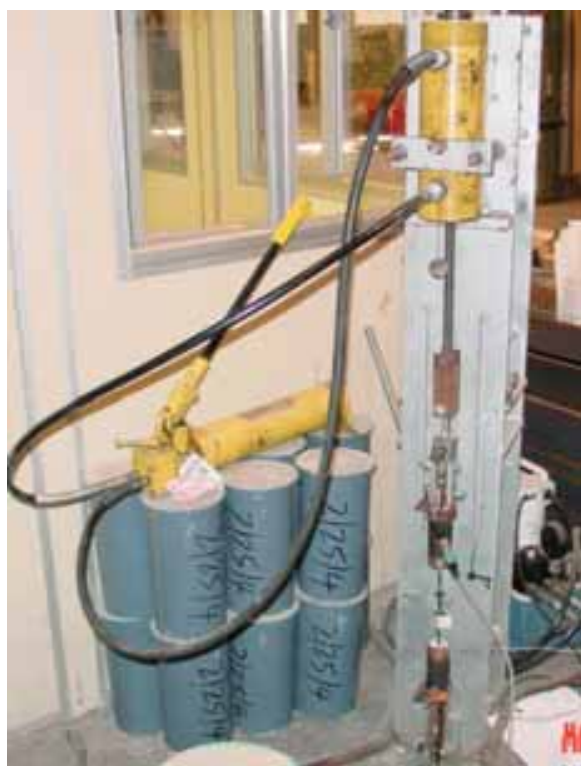

(b)

Figure 2: (a) CFRP grid stand specimen in the testing apparatus, and (b) Test set-up for the tensile testing of the grid strands. 
the strand was embedded into a short section of steel pipe, up to $102 \mathrm{~mm}$. The pipe was filled with an expansive grout leaving a free length of $202 \mathrm{~mm}$. Two foil strain gauges were placed near the middle of the free length of the specimen. Steel angles welded to the opposing ends of the pipe anchors were used to attach the specimen to the loading apparatus (Fig. 2(b)). The loading apparatus consisted of a hydraulic actuator mounted to a stiff steel frame in which load was measured with a ring load cell. The average load rate for the specimens was $145 \mathrm{~N} / \mathrm{s}$, with data acquired approximately every half second.

Table 1 shows the results of the tensile tests. Strands taken from the longitudinal direction are designated longitudinal (L) and strands taken from the transverse direction are designated transverse (T). All specimens ruptured at peak load. Three specimens ruptured away from the anchor and only one close to the anchor. All specimens ruptured at an interception of a longitudinal and a transverse strand. The average peak load per strand was $4.2 \mathrm{kN}$ and is $16.7 \%$ lower than the load provided by the manufacturer $(4.9 \mathrm{kN})$. The average cross-sectional area was $6.26 \mathrm{~mm}^{2}$. The average strength was approximately $695.5 \mathrm{MPa}$ and the average tensile modulus $64.5 \mathrm{GPa}$. The strength of each specimen was calculated by dividing the peak load by the cross-sectional areas, while the modulus was determined by a linear regression of the stress-strain data (Fig. 3). The average of the two strain gauges was used as the strain for each

Table 1: Results from tensile tests of CFRP grid strand specimens.

\begin{tabular}{lccccc}
\hline Specimen & $\begin{array}{c}\text { Grid roll } \\
\text { direction }\end{array}$ & $\begin{array}{c}\text { Area } \\
\left(\mathrm{mm}^{2}\right)\end{array}$ & $\begin{array}{c}\text { Peak load } \\
(\mathrm{kN})\end{array}$ & $\begin{array}{c}\text { Strength } \\
(\mathrm{MPa})\end{array}$ & $\begin{array}{c}\text { Modulus } \\
(\mathrm{GPa})\end{array}$ \\
\hline T1 & Transverse & 7.91 & 3.74 & 473 & 53 \\
T2 & Transverse & 5.86 & 5.10 & 870 & 59 \\
L1 & Longitudinal & 6.08 & 4.11 & 676 & 67 \\
L2 & Longitudinal & 5.18 & 3.96 & 764 & 79 \\
\hline
\end{tabular}

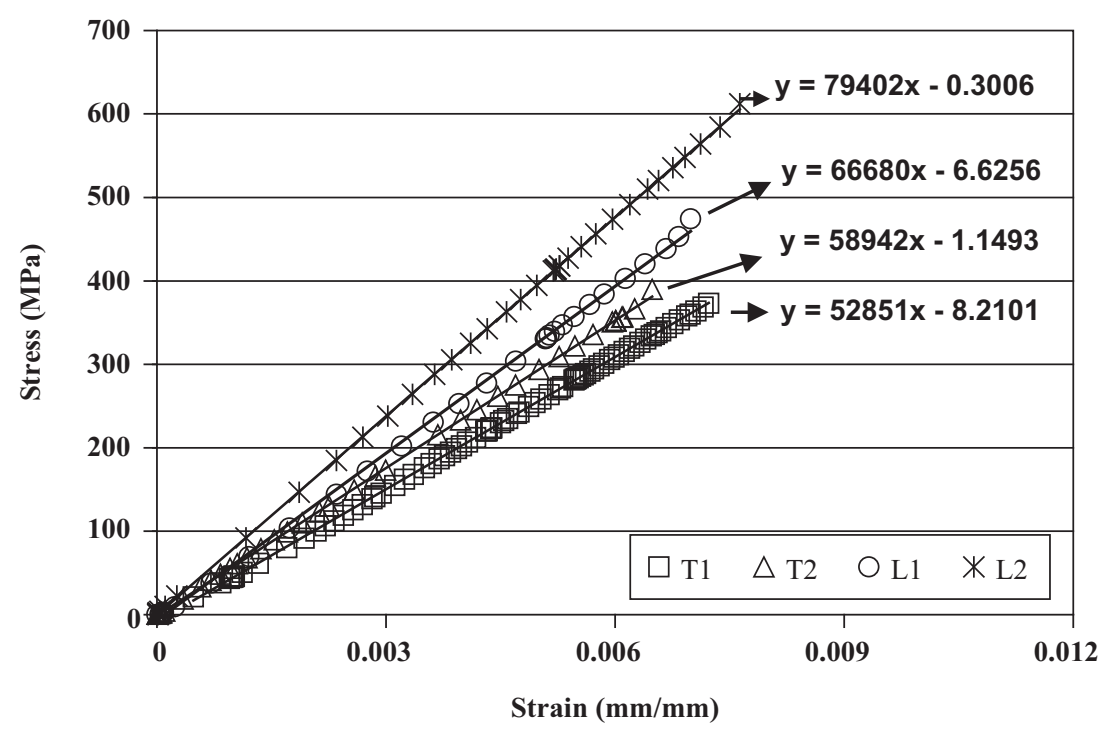

Figure 3: Stress-strain curves of CFRP grid strands tested. 
stress level. The data shown in Fig. 3 do not extend to the rupture strength of the specimen because the strain capacity of the strain gauges was exceeded.

Although insufficient tests were conducted to reveal statistical significance, some indication of strength consistency can be determined from the test data. The coefficient of variance (COV) for the strength was $24 \%$, while that for the tensile modulus $17 \%$. Both COVs are high and can be attributed to the variability between the CFRP strands. Some strands have a thick layer of epoxy resin covering them, which resulted in a lower fiber volume fraction. According to the manufacturing company (TechFab), strands in both the longitudinal and transverse direction have the same capacity. Our tests indicated a 9\% higher capacity for the transverse strands compared to the longitudinal strands but that was attributed to the high variability and the small number of specimens in each direction.

Nine standard $(152 \mathrm{~mm} \times 304 \mathrm{~mm})$ cylinders were cast. Two layers of grid, formed into concentric tubular configurations and held with plastic ties, were cast into six of the specimens, while the remaining three cylinders were cast without reinforcement. The cylinders with the CFRP grid were designated as grid cylinders. The grid cylinders were divided into two groups (three cylinders in each group), with each group having a different grid diameter. The CFRP grid for the first group was formed into a tubular configuration that was approximately 290-mm long with a diameter of $133.4 \mathrm{~mm}$ and the second grid cylinder group had a diameter of $139.7 \mathrm{~mm}$. Two layers of the grid were applied with the grid lapping the two layers for an additional $180 \mathrm{~mm}$ for development purposes. The grid openings were aligned to facilitate the flow of concrete through the grid. The CFRP grid round tubes were placed inside plastic cylinder moulds and concrete was added.

A Class II standard Florida Department of Transportation (FDOT) bridge deck concrete mixture was used to make the cylinders. The specified minimum compressive strength of this concrete at 28 days is $31 \mathrm{MPa}$. Concrete was sampled as per ASTM C172 [15]. Both the control and grid cylinders were cast in the field according to ASTM C31 [16], except that they were ambient cured rather than moist cured.

All concrete cylinders were allowed to cure in the field inside the plastic mould for approximately one month and were then taken to the laboratory where they remained until two weeks before testing. At that time, they were removed from their moulds and sulfur cement caps were placed on each end. The total curing time for all cylinder specimens was 125 days.

Nine cylinders (three controls and six grids) were tested in displacement control mode in order to capture the post-peak behavior of the specimens. Three control cylinders were tested in load control mode using a cylinder tester since no significant post-peak behavior was expected.

The smallest rate that the loading frame could handle was approximately $1.5 \mathrm{~mm}$ per minute that resulted in a load rate of approximately $0.73 \mathrm{MPa}$ per second. This load rate is approximately two times higher than the maximum load rate allowed by ASTM C39 [17]. Therefore, the specimens were loaded faster than the recommended rate.

Two Linear Variable Displacement Transducers (LVDTs) were used to continuously record the length change of the specimens as load was applied. The two LVDTs were placed on opposing sides of the cylinder to determine the average length change of the cylinder specimen. Load and movement data from the loading head as well as data from the LVDTs were collected using a data acquisition program at a rate of $50 \mathrm{~Hz}$. This high rate was necessary to capture the post-peak behavior of the cylinders.

The average strength for the control cylinders tested in displacement control mode was $47.8 \mathrm{MPa}$ and the COV 2\%. Table 2 presents the results from the control cylinders. The control cylinders did not exhibit any significant post-peak behavior but rather crushed after 
Table 2: Results of grid cylinders tested in displacement control mode.

\begin{tabular}{lccccccc}
\hline Type & $\begin{array}{c}\text { Grid } \\
\text { diam. } \\
(\mathrm{mm})\end{array}$ & $\begin{array}{c}\text { Peak } \\
\text { load } \\
(\mathrm{kN})\end{array}$ & $\begin{array}{c}\text { Strain at } \\
\text { peak load } \\
(\mathrm{mm} / \mathrm{mm})\end{array}$ & $\begin{array}{c}\text { Conc. } \\
\text { core area } \\
\left(\mathrm{mm}^{2}\right)\end{array}$ & $\begin{array}{c}\text { Peak } \\
\text { stress } \\
(\mathrm{MPa})\end{array}$ & $\begin{array}{c}\text { Aver. } \\
\text { Stress } \\
(\mathrm{MPa})\end{array}$ & $\begin{array}{c}\text { COV } \\
(\%)\end{array}$ \\
\hline Control 1 & N/A & 854.8 & 0.00251 & 18241 & 46.9 & 47.8 & 2 \\
Control 2 & N/A & 853.2 & 0.00232 & 18241 & 48.8 & & \\
Control 3 & N/A & 870.6 & 0.00236 & 18241 & 47.7 & & \\
Grid 1 & 133.4 & 820.8 & 0.00281 & 13966 & 58.8 & 52.9 & 8.6 \\
Grid 2 & 133.4 & 650.7 & 0.00200 & 13966 & 46.6 & & \\
Grid 3 & 133.4 & 792.6 & 0.00256 & 13966 & 56.8 & & \\
Grid 4 & 139.7 & 743.5 & 0.00279 & 15328 & 49.6 & & \\
Grid 5 & 139.7 & 775.9 & 0.00256 & 15328 & 51.8 & & \\
Grid 6 & 139.7 & 803.7 & 0.00279 & 15328 & 53.7 & & \\
\hline
\end{tabular}

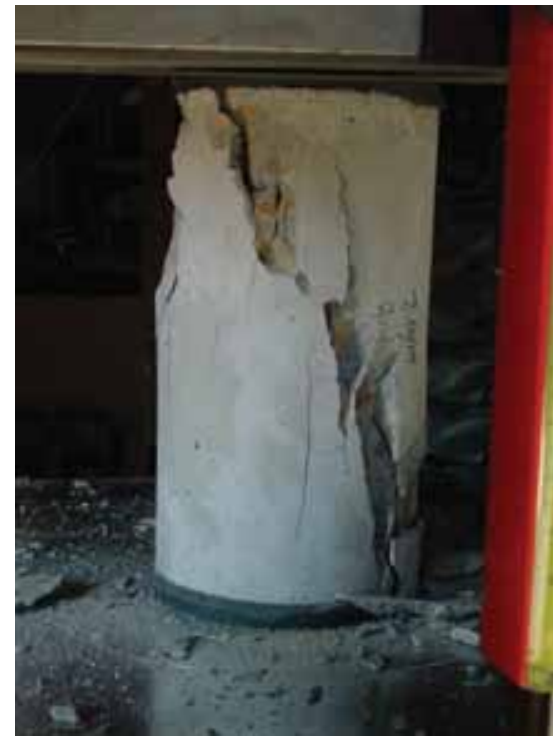

(a)

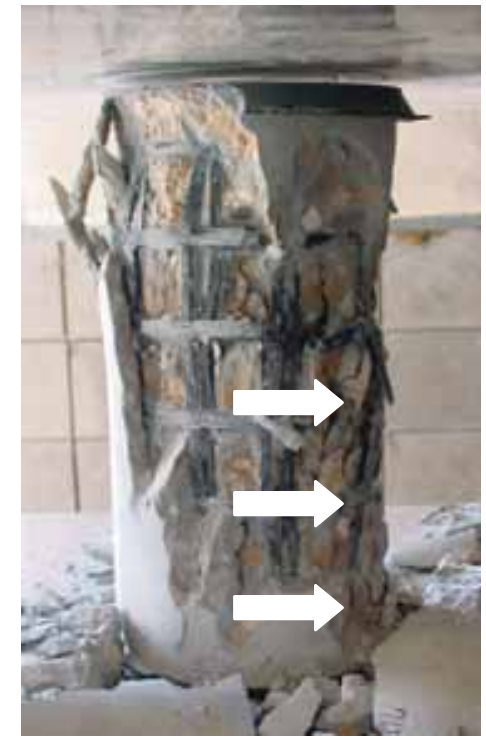

(b)

Figure 4: Typical Tested Cylinders: (a) Control, and (b) Spalled Concrete Cover (12 mm) and Ruptured CFRP Grid Strands (Indicated by Arrows).

reaching the peak load. Typical control cylinder types of fracture were: (a) cone and split and (b) cone and shear. A control cylinder after testing can be seen in Fig. 4(a). The stress-strain curves for the control cylinders are depicted in Fig. 5. The first control cylinder after reaching its peak load lost approximately half of its strength almost immediately, but did not fall apart and continued to carry load contrary to the other two control cylinders that lost all load carrying capacity abruptly soon after peak load.

The average strength of the grid cylinders was $52.9 \mathrm{MPa}$ with a COV of $8.6 \%$. Table 2 contains results from all grid cylinders. Grid cylinders typically failed when CFRP grid 


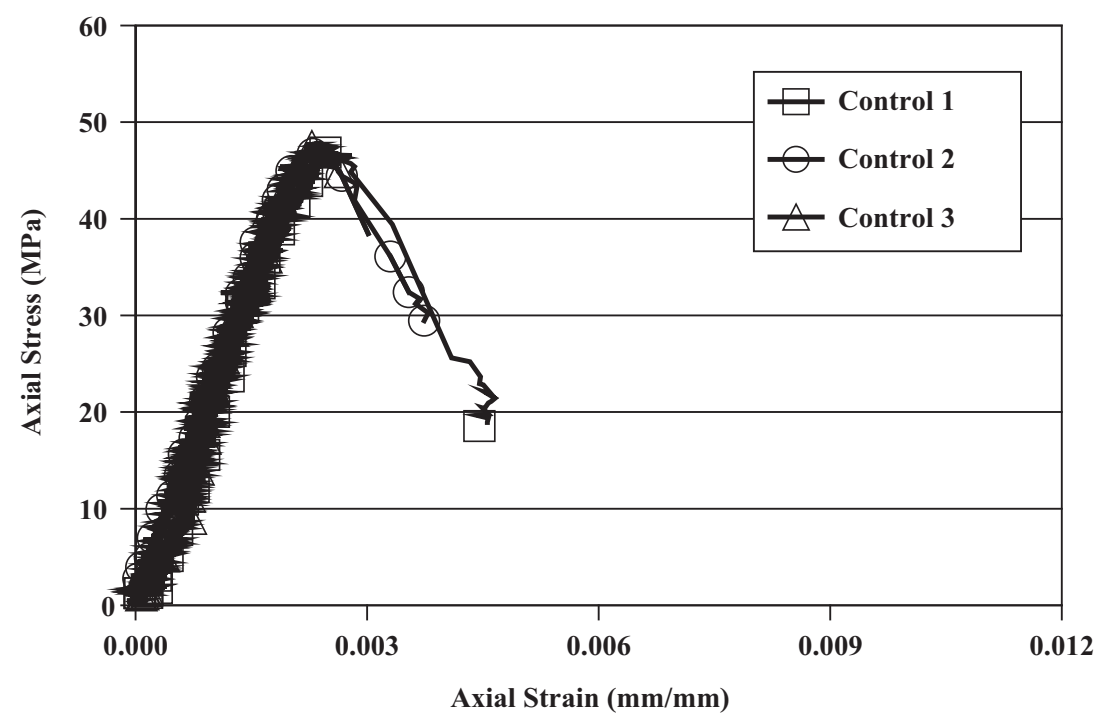

Figure 5: Stress-strain for control cylinders.

strands ruptured. As expected, the concrete cover spalled off the grid specimens before the peak load was reached, but the cylinders maintained most of their load carrying capacity until grid strands started rupturing, which took place in a sequential rather than an abrupt manner. The carbon fibers in the CFRP grid are embedded in an epoxy matrix that creates a smooth surface on the outside faces of the CFRP strands, which may have contributed to spalling. A grid cylinder after testing with ruptured hoop CFRP grid strands can be seen in Fig. 4(b). The stress values for the grid cylinders were calculated based on the area of the concrete core enclosed by the CFRP grid and the axial strain was calculated as the average change in the length, measured by the two LVDTs, of the cylinder over the original length.

The post-peak behavior of the grid cylinders was different compared to the control cylinders. Grid cylinders reached higher peak loads and accommodated larger displacements than the control cylinders. This is especially evident in Fig. 6 where typical experimental stressaxial strain curves from both control and grid specimens were plotted. The area under the post-peak curve of the grid cylinders was approximately three times larger than the area of the control cylinders.

All grid cylinders reached a peak axial load followed by a descending post-peak curve. Other researchers observed such a behavior in lightly confined concrete. Harries and Kharel [8] made similar observations for their one- and two-ply E-Glass confined cylinders. Sfer et al. [18] studied the behavior of concrete under triaxial compression and found that their axial stress-strain curves at low confining pressures had a descending post-peak curve. The increase in the concrete strength was between $10 \%$ and $20 \%$, which compares to the $11 \%$ increase observed for our cylinders. In the case of CFRP grid, confined concrete even with two layers of concrete is still considered lightly confined since the two CFRP grid layers add up to less than one layer of carbon fiber fabric when the CFRP grid strand thickness is spread uniformly over the surface area of the concrete core. In addition, the strength and modulus of the CFRP grid was found to be lower than typical carbon composites, which further reduces its confinement effectiveness. Therefore, the post-peak behavior observed for the CFRP grid cylinders verifies the observations made by Harries and Kharel [8] and Sfer et al. [18]. 


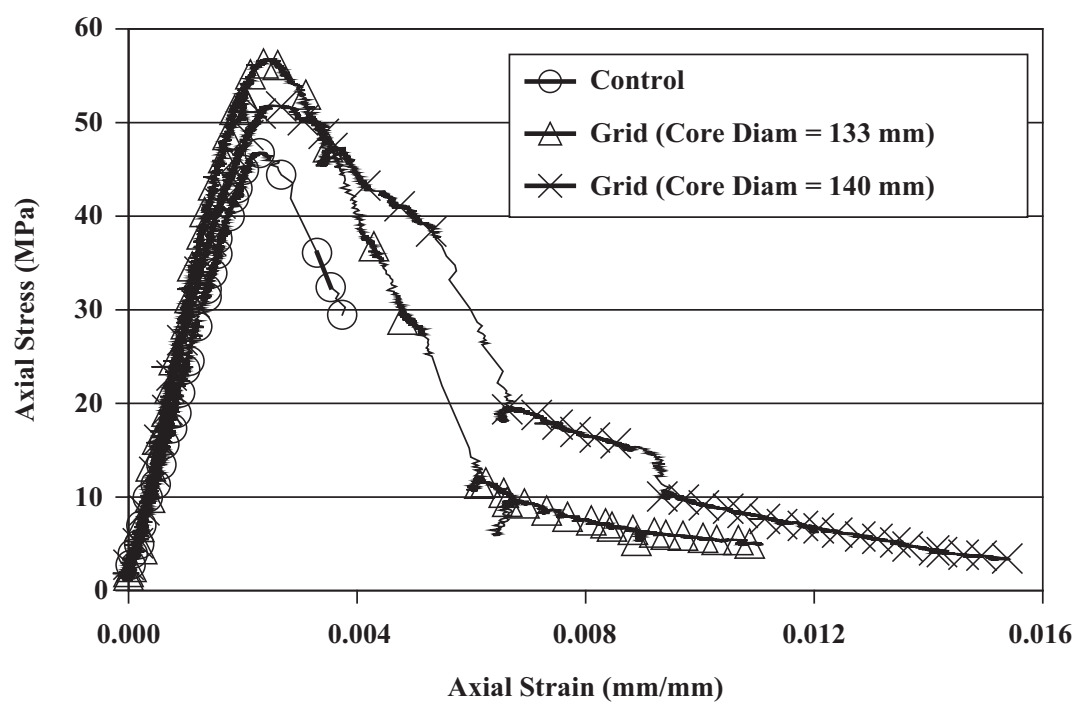

Figure 6: Stress-strain curves for typical control and grid cylinders.

\subsubsection{Confinement models}

Most models for concrete confined with CFRP reinforcement are based on the fact that in most cases even one layer of carbon fabric or a carbon jacket will provide enough reinforcement to have highly confined concrete. Therefore, the confinement effectiveness is high leading to a failure of the CFRP jacket or encasement at peak axial stress.

When the CFRP grid is used as confinement reinforcement, the confining pressure and confinement effectiveness is low, and therefore models developed using data from relatively high confined concrete may not be adequate. To model the behavior of CFRP grid, existing confined concrete models were used. Existing models are based on a constant thickness of the FRP material that covers the entire surface area of the confined concrete core. Michael et al. [1] used the modified Hognestad stress-strain curve to model the behavior of CFRP grid confined concrete as shown in Fig. 7 [1]. In Fig. 7, $\varepsilon_{c}$ is the concrete strain, $\varepsilon_{o}$ is the strain at peak stress of unconfined concrete, and $\varepsilon_{c u}$ is the ultimate strain. The modified Hognestad parabola consists of two regions. In region $\mathrm{AB}\left(\varepsilon_{c}<\varepsilon_{o}\right)$, the Hognestad parabola is used and in region $\mathrm{BC}\left(\varepsilon_{o}<\varepsilon_{c}<\varepsilon_{c u}\right)$, a linearly descending curve. The equation for region $\mathrm{BC}$ is based on the deterioration constant $\left(D_{c}\right)$ that controls the slope of the line. The equations for the two regions were modified to model the behavior of CFRP grid concrete. The material properties of the CFRP grid strands were used in the process of constructing the stress-strain curve of the CFRP grid confined concrete. The average strength of the control cylinders tested in deflection control model was taken as the strength of unconfined concrete $\left(f^{\prime}{ }_{c}\right)$. The ultimate concrete strain $\varepsilon_{c u}$ was assumed to be $0.00725 \mathrm{~mm} / \mathrm{mm}$. The deterioration constant was taken equal to 130 to match post-peak experimental data. All three curves are depicted in Fig. 8. The modified Hognestad matches well with the experimental curve.

When concrete sections are wrapped with CFRP fabrics, the concrete in the sections is usually highly confined, provided that enough CFRP composite material is used to develop high 


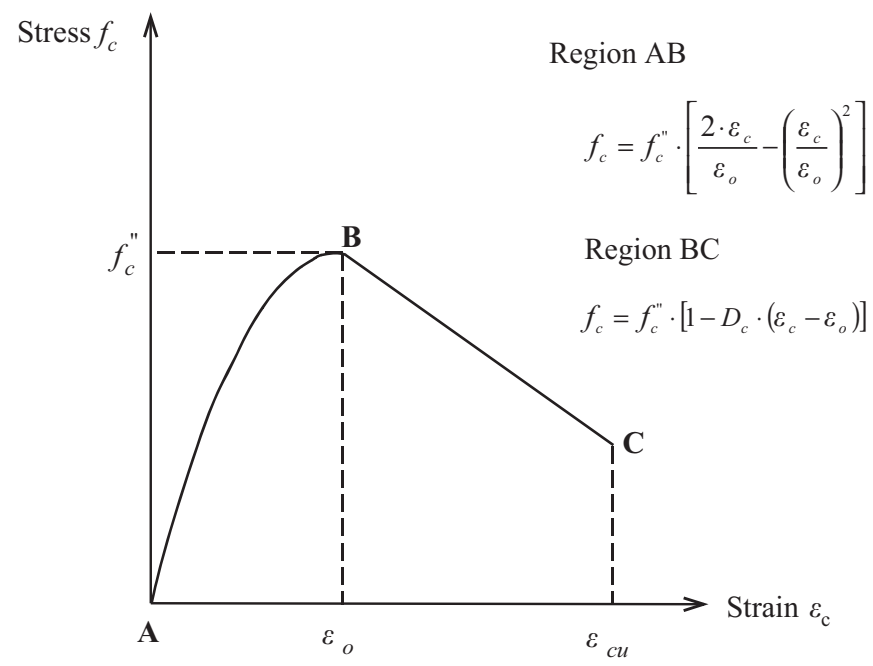

Figure 7: Modified Hognestad Parabola used for the modeling of confined concrete [1].

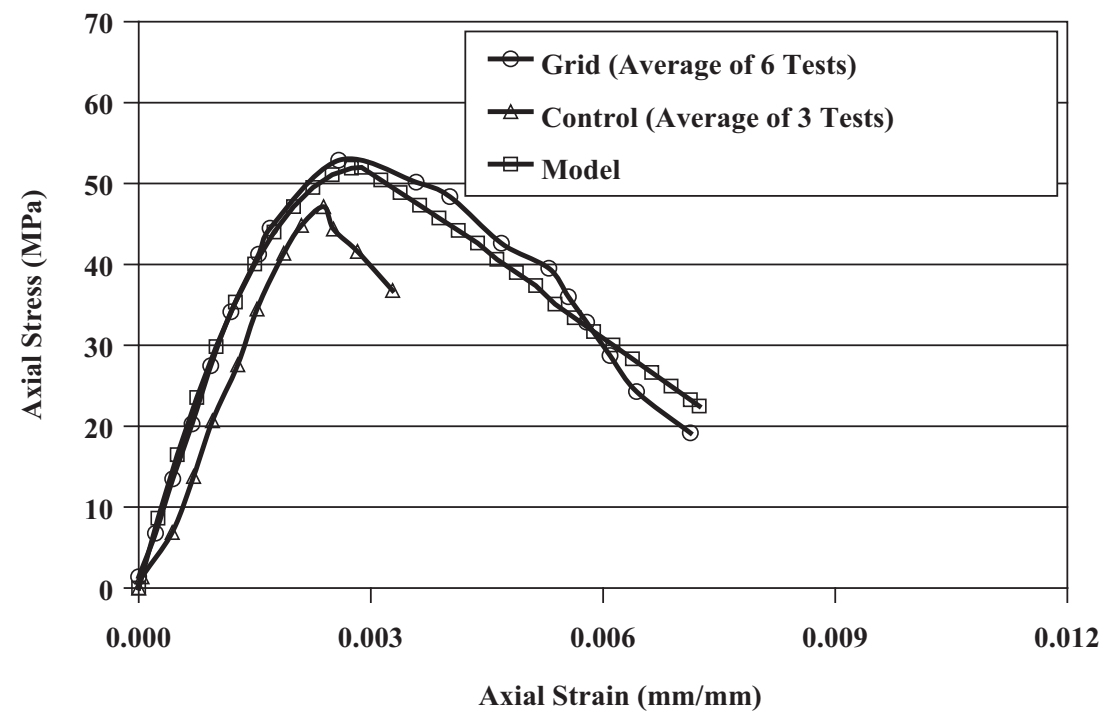

Figure 8: Concrete modelling as obtained by experimental data.

confining pressures. In those cases, the increase in the strength and ductility of the confined concrete is significantly higher than the increase and ductility of lightly confined concrete. In order to evaluate the effect of highly confined concrete on the interaction diagrams of concrete sections, a design-oriented model proposed by Lam and Teng [19] was employed to characterise the stress-strain behavior of confined concrete. Lam and Teng [19] developed a design-oriented concrete confinement model that predicts the stress-strain behavior of highly 
confined concrete. The model is simple and the basic assumptions are: (a) the stress-strain curve consists of an initial parabolic section and a straight line second section, (b) the initial slope of the parabola is the same as the elastic modulus of the unconfined concrete, (c) the parabolic section is only partly affected by the FRP jacket, (d) smooth transition between the parabolic and straight line portions, and (e) failure occurs at the maximum axial strain and strength of the confined concrete.

\subsection{Plastic centroid}

Reference must be made as to the point about which the moments are calculated. We refer to this point as the plastic centroid, and it is the point of action of the axial load when there is a uniform maximum compressive strain. This assures that the moment capacity of the section is zero at maximum axial load capacity.

\section{DEVELOPMENT OF THE INTERACTION DIAGRAM}

The development of interaction diagram is based on the calculation of a series of points representing failure in the concrete subjected to maximum compressive strain and a specified strain in the extreme steel fiber. A number of points, axial force vs bending moment ( $\mathrm{Pn}, \mathrm{Mn})$, are calculated in order to define the failure curve of the section. The calculation of individual points ensures equilibrium of the section and it includes:

- Definition of the neutral axis location

- Calculation of the plastic centroid

- Definition of the strain plane over the entire section

- Calculation of strains using compatibility and the corresponding stresses based on the stress vs strain relationship

- Integration of stresses over the section to calculate the axial force and the bending moment

\subsection{Neutral axis location}

The neutral axis location is calculated using the values of the maximum compressive strain in the concrete, $\varepsilon_{c u}$, and a variable value for the strain in the extreme reinforcing steel fiber, $\varepsilon_{s t}$. Each combination of strains $\left(\varepsilon_{c u}, \varepsilon_{s t}\right)$ will define a strain distribution over the section at failure, and thus, a point on the interaction diagram (axial load vs bending moment). Calculation of the neutral axis in a circular section can take advantage of the symmetry of the section. One point on the section $\left(\mathrm{P}_{1}\right)$ is assigned the maximum compressive strength, and it is considered the extreme concrete compression fiber. The extreme steel fiber is located at the steel bar, which is located at the maximum distance from the extreme compression fiber. Having the location of the two extreme fibers and the values of the corresponding strains, the neutral axis can be defined as shown in Fig. 9.

\subsection{Plastic centroid location}

For symmetrical sections, both in concrete geometry and the reinforcement distribution, the plastic centroid (pc) coincides with the geometric centroid $(\mathrm{gc})$. When this is not the case then the location of the plastic centroid has to be calculated accounting for the concrete geometry as well as the area and location of each reinforcing bar. 


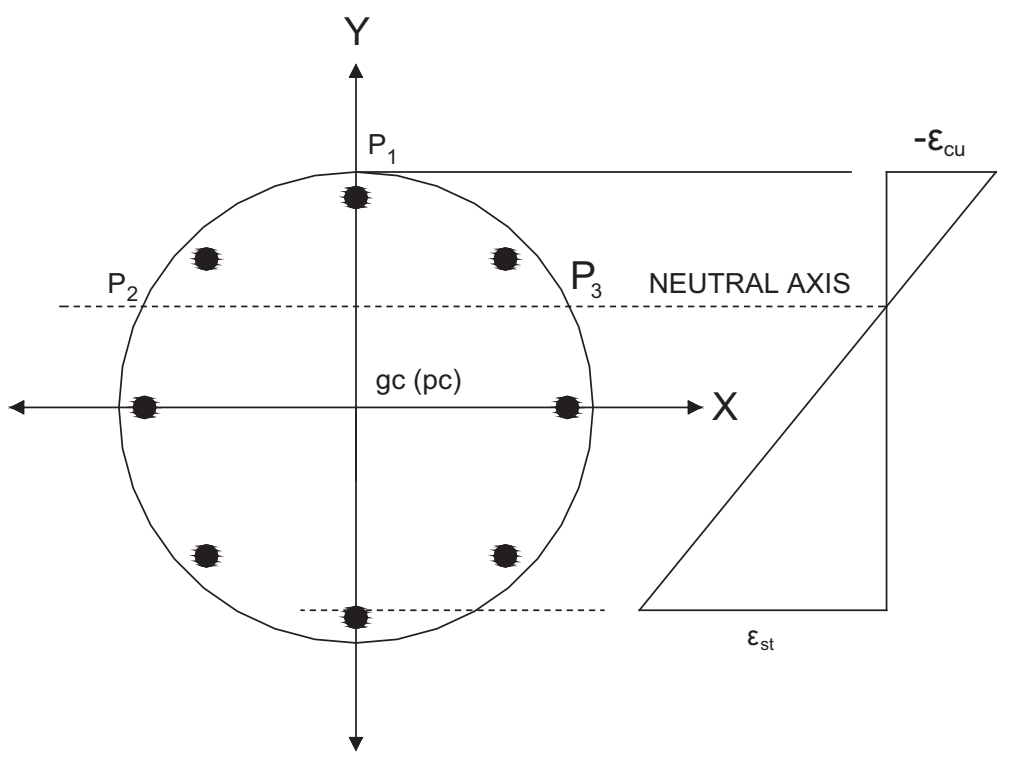

Figure 9: Circular cross section.

\subsection{Strain plane and calculation of strains}

When the neutral axis is defined, the distribution of the strain over the whole section can be defined with the calculation of a strain plane. The strain plane is defined using two points on the line of neutral axis $\left(\mathrm{P}_{2}, \mathrm{P}_{3}\right)$ and the point at extreme compression fiber $\left(\mathrm{P}_{1}\right)$ as shown in Fig. 9.

Using the strain plane equation, a strain value for any point on the section can be defined. Based on the strain and the stress vs strain relationship of the material, the stress at each point can be obtained using eqn 1 .

$$
d F_{i}=\sigma_{i} d A_{i}
$$

\subsection{Integration of stresses to calculate axial load and bending moment}

The axial load $\left(\mathrm{P}_{\mathrm{n}}\right)$ and bending moment $\left(\mathrm{M}_{\mathrm{n}}\right)$ can be calculated by the integration of stresses over the section. This can be done using eqns 2 and 3:

$$
\begin{gathered}
P=\iint_{A} d F_{i}=\iint_{A} \sigma_{i} d A \\
M=\iint_{A} d F_{i} x=\iint_{A} \sigma_{i} x d A
\end{gathered}
$$

4.5 Numerical procedure for generation of the interaction diagram

Direct integration for calculation of the axial load as well as the moment is not trivial. For this reason, a numerical procedure (and accompanying software) was developed and used in this work for generation of interaction diagrams. The range of axial loads spans from the maximum 
compressive axial load to the axial load of pure tension. In order to numerically generate the diagram, four points are identified on it (Fig. 1).

- Point \#1: Fracture failure point (pure tension)

- Point \#2: Zero axial load point

- Point \#3: Balanced point

- Point \#4: Maximum compressive axial load point (pure compression)

These points are calculated independently and they define three sub-regions on the diagram. For each point, the important element to be known is the value of the net tensile strain at the extreme tension reinforcement fiber. The strains at Point \#1, Point \#3, and Point \#4 are known directly from material properties. The other one has to be calculated. The strain at Point \#2 represents the point with zero axial load. However, the strain in the extreme reinforcement bar is not known. As a result, an iteration convergence procedure (secant method) is used to calculate the strain in the extreme steel fiber when the axial load equals to zero. Once the strains for the boundary points of the sub-regions are defined, the diagram can be generated by assigning different values of strains for the extreme steel fiber in each sub-region, and thus, calculating intermediate points within the sub regions on the interaction diagram. Figure 10 shows the flowchart of the numerical procedure.
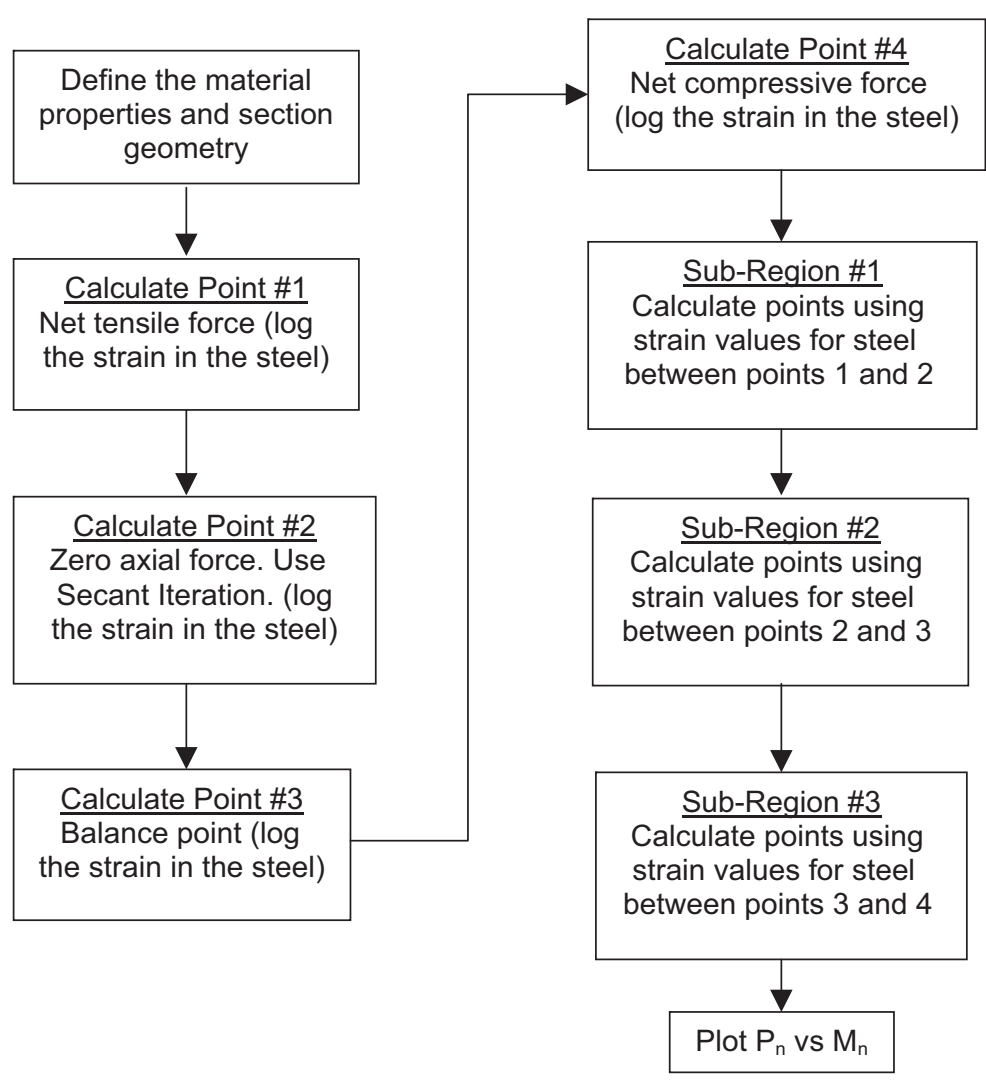

Figure 10: Flowchart describing the numerical procedure. 


\section{CASE STUDIES}

The presented procedure has been used for development of the interaction diagram of different sections. Figure 11 shows the interaction diagram of the same section with three different levels of confinement. The inner line shows the unconfined section. The other lines show the interaction diagrams with increased concrete confinement: (a) light confinement, (b) heavy confinement with 1.5-mm-thick CFRP composite wrap, and (c) heavy confinement with 2.5-mm-thick CFRP composite wrap.

\subsection{Section data}

Table 3 shows the data used for generation of interaction diagrams.

Table 3: Data for generation of interaction diagrams.

\begin{tabular}{lcccccc}
\hline Section & $\begin{array}{c}\text { Radius } \\
(\mathrm{m})\end{array}$ & $\begin{array}{c}\text { Steel } \\
\text { reinf. }\end{array}$ & $\begin{array}{c}\text { Ultimate } \\
\text { concrete } \\
\text { strain, } \varepsilon_{c u} \\
(\mathrm{~mm} / \mathrm{mm})\end{array}$ & $\begin{array}{c}\text { Type of } \\
\text { CFRP }\end{array}$ & $\begin{array}{c}\text { Thick. of } \\
\text { CFRP } \\
(\mathrm{mm})\end{array}$ & $\begin{array}{c}\text { Strength } \\
\text { of CFRP } \\
(\mathrm{MPa})\end{array}$ \\
\hline UC & 0.2 & $8 \mathrm{Y} 16$ & 0.003 & N/A & N/A & N/A \\
LC & 0.2 & $8 Y 16$ & 0.007 & GRID & $1 /$ strand & 696 \\
HC1 & 0.2 & $8 Y 16$ & 0.018 & WRAP & 1.5 & 1577 \\
HC2 & 0.2 & $8 Y 16$ & 0.018 & WRAP & 2.5 & 1577 \\
\hline
\end{tabular}

UC: Unconfined, LC: Light confinement, HC: Heavy confinement.

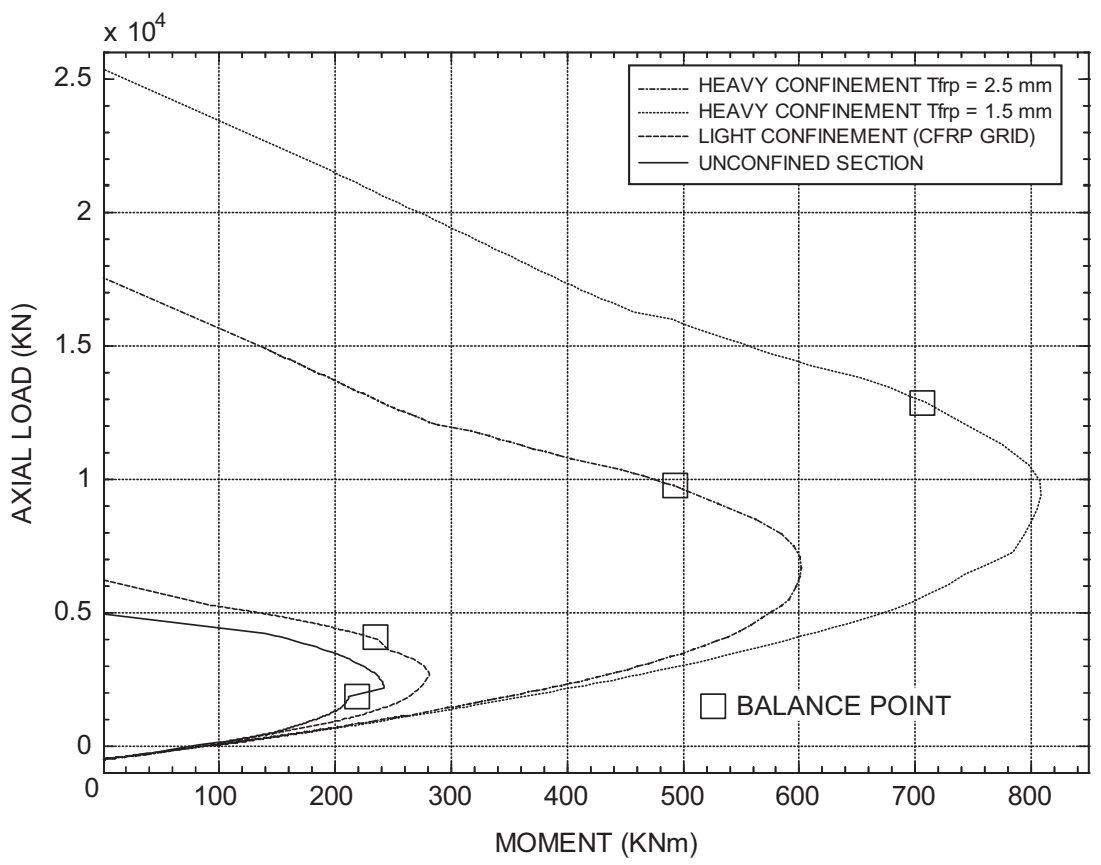

Figure 11: Interaction diagrams of sections with variable concrete confinement. 
Table 4: Maximum axial load and bending moment ratios.

\begin{tabular}{lcccccc}
\hline & $\begin{array}{c}\text { Max. comp. } \\
\text { axial load, } \\
P n(\mathrm{kN})\end{array}$ & $P n / P n_{U C}$ & $\begin{array}{c}\text { Max. } \\
\text { moment } M n, \\
(\mathrm{kNm})\end{array}$ & $\begin{array}{c}M n / \\
M n_{U C}\end{array}$ & $\begin{array}{c}\text { Max. tensile } \\
\text { axial load, } \\
P n t(\mathrm{kN})\end{array}$ & $P n t / P n t_{U C}$ \\
\hline UC & 5000 & 1.0 & 240 & 1 & 500 & 1 \\
LC & 6200 & 1.24 & 280 & 1.17 & 500 & 1 \\
HC1 & 17500 & 3.5 & 600 & 2.5 & 500 & 1 \\
HC2 & 25300 & 5.06 & 810 & 3.38 & 500 & 1 \\
\hline
\end{tabular}

UC: Unconfined, LC: Light confinement, HC: Heavy confinement.

\subsection{Discussion}

Looking at the plots on Fig. 11, it is obvious that there is a trend defined as the value of the maximum compressive strength is increased. Specifically, we see that the plots look virtually the same at the tension-controlled regions and they diverge in the compression-controlled regions as the maximum compressive strength increases. The maximum compressive strength obviously increases as the level of confinement increases. It is interesting to point out that the value of the maximum compressive strain, $\varepsilon_{c u}$, does not have a significant effect on the shape of the interaction diagram. It is also interesting to note that the balance point for both light and heavy confinement moved higher up on the interaction diagram. As a result, the steel reinforcement reaches its yield strength for a larger range of values of axial compression and bending moment. Therefore, there is an increase of ductility, which is gained due to the confinement. The decisive factor that affects the section capacity is the maximum compressive strength of concrete.

The maximum axial loads (both compressive and tensile) and the maximum bending moments for all sections compared to the unconfined section based on the interaction diagrams are shown in Table 4. As seen from the numbers, there is a significant increase in all of the above parameters. This increase is much more prominent in the case of heavy confinement than in the case of light confinement compared to the unconfined section. For example, the maximum compressive strength of the lightly confined section is 1.24 times higher compared to the maximum compressive strength of the unconfined section. Heavy confinement sections have maximum compressive strengths 3.5 to 5 times that of the unconfined section. Similar trends are observed for the maximum moment. Maximum moment for the lightly confined section is 1.17 times higher than the maximum moment of the unconfined sections, while for the heavy confined sections it is 2.5 (HC1) and 3.38 (HC2) times higher compared to the maximum moment of the unconfined section. The maximum tensile load remains unchanged due to the fact that we ignore the tensile strength of concrete and any tensile contribution from the CFRP composite material based on the assumption that all fibers of the CFRP composite material are oriented in the hoop direction, and therefore, no fibers exist in the axial direction to provide any additional tensile resistance to the confined section.

\section{CONCLUSIONS}

Based on the results and findings presented in the paper, following conclusions can be drawn:

- Confinement increases the maximum compressive strength of the section for both light confinement (approximately 25\%) and heavy confinement (up to 500\%). 
- Confinement affects significantly the capacity of the section when the section is in the compression-controlled region (pure compression to balance point).

- The effect of confinement is relatively small in the region between pure bending and the balance point.

- The balance point for both light and heavy confinement moved higher up on the interaction diagram (Fig. 11), which can lead us to the conclusion that for a larger range of values of axial compression and bending moment, steel reinforcement reaches its yield strength. The compressive capacity of the section at the balanced point is increased up to $600 \%$ compared to the unconfined section. The flexural capacity of the section at the balanced point is also increased up to $335 \%$ compared to the unconfined section. The shift of the balance point location changes the range of the compression and tension zones on the interaction diagram.

- Confinement has no effect on the region between pure tension and pure bending since concrete is primarily in tension (Fig. 11). Therefore, the presence of reinforcement in the hoop direction offers no improvement in concrete tensile strength.

- Based on significant changes in the interaction diagram from the effect of confinement, it is necessary to evaluate the design approach to compression members confined with CFRP composite materials. Ignoring the effect of confinement can lead to conservative designs (larger sections) and increases in the material and construction costs. In order to do that, design interaction diagrams would be helpful. However, the development of design equations that take into account the effect of confinement and can be included in design codes would be even more helpful since they could be programmed into available software packages.

- Although this is not evident from the interaction diagrams, the failure mode of compressioncontrolled columns (failure by concrete crushing) is more ductile due to the change in the behavior of concrete due to confinement (Confined concrete fails in a ductile manner).

\section{ACKNOWLEDGEMENTS}

The authors would like to thank the FDOT for providing the CFRP composite grid testing data as well as the data for confined cylinders using the CFRP composite grid. The authors gratefully acknowledge the contributions of Steve Eudy, Frank Cobb, Tony Johnston, Paul Tighe, and David Allen of the FDOT.

\section{REFERENCES}

[1] Michael, A. P., Hamilton, H. R., III \& Ansley, M. H., Concrete Confinement Using Carbon Fiber Reinforced Polymer Grid, 7th International Symposium on Fiber Reinforced Polymer (FRP) Reinforcement for Concrete Structures (ACI 2005 Fall Convention), Vol. 2, American Concrete Institute: Kansas City, MO, pp. 991-1010, 2005.

[2] Bresler, B., Design criteria for reinforced concrete columns under axial load and biaxial bending. ACI Journal, Proceedings, 57, 1960.

[3] Parme, A. L., Nieves, J.M. \& Gouwens, A., Capacity of reinforced rectangular columns subjected to biaxial bending. ACI Journal, Proceedings, 63(9), 1966.

[4] Xiao, Y. \& Wu, H., Compressive behavior of concrete confined by Carbon Fiber composite jackets. Journal of Materials in Civil Engineering, 12(2), pp. 139-146, 2000. doi: http://dx.doi.org/10.1061/(ASCE)0899-1561(2000)12:2(139)

[5] Xiao, Y. \& Wu, H., A Constitutive model for concrete confinement with Carbon Fiber reinforced plastics. Journal of Reinforced Plastics and composites, 22(13), pp. 1187-1201, 2003. doi: http://dx.doi.org/10.1177/0731684403035430 
[6] Lam, L. \& Teng, J.G., Ultimate condition of Fiber reinforced polymer-confined concrete. Journal of Composites for Construction, 8(6), pp. 539-548, 2004. doi: http:// dx.doi.org/10.1061/(ASCE)1090-0268(2004)8:6(539)

[7] Li, Y., Lin, C. \& Sung, Y., Compressive behavior of concrete confined by various types of FRP composite jackets. Mechanics of Materials, 35(3-6), pp. 603-619, 2002.

[8] Harries, K.A. \& Kharel, G., Experimental investigation of the behavior of variably confined concrete, Cement and Concrete Research, 33(6), pp. 873-880, 2002. doi: http:// dx.doi.org/10.1016/S0008-8846(02)01086-4

[9] Li, J. \& Hadi, M.N.S., Behaviour of externally confined high-strength concrete columns under eccentric loading. Composite Structures, 62(2), pp. 145-153, 2003. doi: http:// dx.doi.org/10.1016/S0263-8223(03)00109-0

[10] Campione, G. \& Miraglia, N., Strength and strain capacities of concrete compression members reinforced with FRP. Cement and Concrete Composites, 25(1), pp. 31-41, 2003. doi: http://dx.doi.org/10.1016/S0958-9465(01)00048-8

[11] Teng, M., Sotelino, E.D. \& Chen, W., Performance evaluation of reinforced concrete bridge columns wrapped with Fiber reinforced polymers. Journal of Composites for Construction, 7(2), pp. 83-92, 2002. doi: http://dx.doi.org/10.1061/(ASCE)1090$\underline{0268(2003) 7: 2(83)}$

[12] Shahawy, M, Mirmiran, A. \& Beitelman, T., Tests and modeling of Carbon-wrapped concrete columns, Composites Part B: Engineering, 31(6-7), pp. 471-480, 2000. doi: http://dx.doi.org/10.1016/S1359-8368(00)00021-4

[13] Davol, A., Burgueno, R. \& Seible, F., Flexural behavior of circular concrete filled FRP shells, Journal of Structural Engineering, 127(7), pp. 810-817, 2001. doi: http://dx.doi. org/10.1061/(ASCE)0733-9445(2001)127:7(810)

[14] Park, R. \& Paulay, T., Ultimate deformation and ductility of members with flexure (Chapter 6). Reinforced Concrete Structures, John Wiley \& Sons, New York, pp. 195-269, 1975.

[15] ASTM C172, Standard Practice for Sampling Freshly Mixed Concrete, American Society for Testing and Materials, 100 Barr Harbor Drive, West Conshohocken, PA 19428.

[16] ASTM C 31, Standard Practice for Making and Curing Concrete Test Specimens in the Field, American Society for Testing and Materials, 100 Barr Harbor Drive, West Conshohocken, PA 19428.

[17] ASTM C 39, Standard Test Method for Compressive Strength of Cylindrical Concrete Specimens, American Society for Testing and Materials, 100 Barr Harbor Drive, West Conshohocken, PA 19428.

[18] Sfer, D., Carol, I., Gettu, R. \& Etse, G., Study of the behavior of concrete under triaxial compression. Journal of Engineering Mechanics, 128(2), pp. 156-163, 2002. doi: http://dx.doi.org/10.1061/(ASCE)0733-9399(2002)128:2(156)

[19] Lam L. and Teng, J.G., Design-Oriented stress-strain model for FRP-confined concrete, Construction and Building Materials, 17, pp. 471-489, 2003. doi: http://dx.doi.org/ $\underline{10.1016 / \mathrm{S} 0950-0618(03) 00045-\mathrm{X}}$ 